\title{
Dovitinib preferentially targets endothelial cells rather than cancer cells for the inhibition of hepatocellular carcinoma growth and metastasis
}

\author{
Zhi-Yuan Chen ${ }^{1,2,3 \dagger}{ }^{+}$, Ming Shi ${ }^{1,2 \dagger}$, Li-Xia Peng ${ }^{2,3}$, Wei Wei ${ }^{1,2}$, Xin-Jian Li ${ }^{2,4}$, Zhi-Xing Guo ${ }^{1,2}$, Shu-Hong Li ${ }^{1,2}$, \\ Chong Zhong ${ }^{5}$, Chao-Nan Qian $2,3^{*}$ and Rong-Ping Guo $0^{1,2^{*}}$
}

\begin{abstract}
Background: Dovitinib is a receptor tyrosine kinase (RTK) inhibitor targeting vascular endothelial growth factor receptors, fibroblast growth factor receptors and platelet-derived growth factor receptor $\beta$. Dovitinib is currently in clinical trials for the treatment of hepatocellular carcinoma (HCC).

Method: In this study, we used five HCC cell lines and five endothelial cell lines to validate molecular and cellular targets of dovitinib.

Results: Tumor growth and pulmonary metastasis were significantly suppressed in an orthotopic HCC model. Immunoblotting revealed that among known dovitinib targets, only PDGFR- $\beta$ was expressed in two HCC cell lines, while four of five endothelial lines expressed PDGFR- $\beta$, FGFR-1, and VEGFR-2. Dovitinib inhibited endothelial cell proliferation and motility at $0.04 \mu \mathrm{mol} / \mathrm{L}$, a pharmacologically relevant concentration; it was unable to inhibit the proliferation or motility of HCC cells at the same concentration. Immunohistochemical analyses showed that dovitinib significantly decreased the microvessel density of xenograft tumors, inhibiting proliferation and inducing apoptosis in HCC cells.
\end{abstract}

Conclusion: Our findings indicate that dovitinib inhibits HCC growth and metastasis preferentially through an antiangiogenic mechanism, not through direct targeting of HCC cells.

Keywords: Dovitinib, Endothelial cells, Hepatocellular carcinoma, Tumor growth, Tumor metastasis

\section{Introduction}

Hepatocellular carcinoma (HCC) is characterized by highly vascularized and rapid tumor progression, a high recurrence rate after surgical resection, and an extremely poor prognosis. It is the fifth most common cancer in the world, and the third most frequent cause of cancer death [1-4]. The highly vascularized nature of HCC has been considered as the main reason for its devastating outcome, because of intrahepatic and distant metastases [5-7]. Vascular endothelial growth factor (VEGF), basic fibroblast growth factor (bFGF), and platelet-derived

\footnotetext{
* Correspondence: qianchn@sysucc.org.cn; guorp@sysucc.org.cn

${ }^{\dagger}$ Equal contributors

${ }^{2}$ State Key Laboratory of Oncology in South China, Sun Yat-sen University Cancer Center, 651 Dongfeng East Road, Guangzhou 510060, People's Republic of China

${ }^{3}$ Laboratory of Cancer and Developmental Cell Biology, Van Andel Research Institute, 333 Bostwick Ave. NE, Grand Rapids, Ml 49503, USA

Full list of author information is available at the end of the article
}

growth factor (PDGF) are three important proangiogenic factors involved in hepatocarcinogenesis, and they participate in the neovascular, invasive, and metastatic potentials of HCC [8-11].

VEGF expression is detected in dysplastic nodules and correlates with histological grades; VEGF is increased during hepatocarcinogenesis [8]. Sorafenib, an inhibitor of several kinases, including Raf- 1 and VEGF receptor (VEGFR), is currently the first-line therapy for advanced or recurrent HCC. It has a modest survival benefit, but patients develop subsequent drug resistance [12-14].

Dovitinib (TKI258; formerly CHIR258) is a potent inhibitor of receptor tyrosine kinases (RTKs). It inhibits VEGFR-1, VEGFR-2, and VEGFR-3; fibroblast growth factor receptors (FGFR1, FGFR2, and FGFR3); and platelet-derived growth factor receptor $\beta$ (PDGFR- $\beta$ ) $[15,16]$. Dovitinib is reported to directly inhibit the proliferation and survival of colon cancer and leukemia

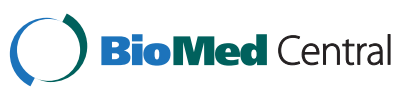


cells, which harbor either activating mutations or translocations in the target RTKs or their ligands, at pharmacologically relevant concentrations of $0.01-0.3 \mu \mathrm{mol} / \mathrm{L}$ [17-19].

In preclinical studies, dovitinib has been able to inhibit xenograft HCC growth in immunodeficient mice and even overcome sorafenib resistance [20,21]. However, the lack of somatic mutations of RTK genes in HCC has caused doubt about whether HCC cells are the primary cellular target of dovitinib [22]. It has been reported that endothelial cells and perivascular cells (pericytes) can express VEGFR, PDGFR, and/or FGFR [8,23,24]; thus, these cells are theoretical targets of dovitinib, and the drug might act as an angiogenesis inhibitor in vivo. However, the ability of dovitinib to suppress tumor angiogenesis has not been established.

In the present study, our aim was to reveal the cellular targets of dovitinib in HCC treatment at pharmacologically relevant concentrations, which is crucial for the future development of this treatment strategy.

\section{Materials and methods \\ Kinase inhibitor}

Dovitinib (CHIR-258, TKI258) [4-amino-5-fluoro-3-[6 (4-methyl-1-piperazinyl)-1H- benzimidazol-2-yl]-2(1H)quinolinone], with a molecular weight of 392.4, was provided by Novartis Pharma AG (Novartis Institutes for Biomedical Research, Basel, Switzerland).

\section{Cells and cell culture}

The human HCC cell lines MHCC-97H, QGY-7703, SMMC7721, Hep3B, and CRI2234, as well as a human bone marrow endothelial (HBME) line, were maintained in DMEM or RPMI 1640 (Invitrogen) supplemented with $10 \%$ fetal bovine serum (FBS; Invitrogen), $100 \mathrm{IU} / \mathrm{mL}$ penicillin, and $100 \mu \mathrm{g} / \mathrm{mL}$ streptomycin (Invitrogen) in a humidified incubator containing $5 \% \mathrm{CO}_{2}$ at $37^{\circ} \mathrm{C}$. Human umbilical vascular endothelial cells (HUVECs), human dermal microvascular endothelial cells (HMVECs), human umbilical artery endothelial cells (HUAECs), and human lung microvascular endothelial cells (HLMVECs) were maintained in Clonetics Endothelial Basal Medium-2 (EBM-2) supplemented with essential growth factor supplements EGM-2 SingleQuots or EGM-MV SingleQuots (Lonza). All the cell lines were used within 50 passages.

\section{Cell viability assay}

Cell viability was assessed using an 3-(4,5-dimethylthiazol 2-yl)-5-(3-carboxymethoxyphenyl)-2-(4-sulfophenyl)$2 \mathrm{H}$-tetrazolium (MTS) assay kit (Sigma) with dye conversion at $490 \mathrm{~nm}$, following the manufacturer's instructions. Briefly, cells were seeded $3 \times 10^{3} /$ well in a 96-well flatbottomed plate and starved in no serum for $18 \mathrm{~h}$, and were then treated with increasing concentrations of dovitinib and stimulated with $30 \mathrm{ng} / \mathrm{mL}$ recombinant human VEGF or PDGF-BB (Sigma V7259 or SRP3138). At $72 \mathrm{~h}$, $20 \mu \mathrm{l}$ of MTS was added to each well. After $1.5 \mathrm{~h}$ of incubation at $37^{\circ} \mathrm{C}$, the results were analyzed by a plate reader at $490 \mathrm{~nm}$. The sample data was normalized to background readings of medium only.

\section{In vitro migration and invasion assays}

For Transwell migration assays, $5.0 \times 10^{4} \mathrm{HCC}$ cells or endothelial cells in $500 \mu \mathrm{l}$ of serum-free DMEM or EBM were added to the cell culture inserts with an $8-\mu \mathrm{m}$ microporous filter without an extracellular matrix coating (Becton Dickinson Labware). To the bottom chamber was added $800 \mu \mathrm{L}$ of DMEM or EGM containing $10 \%$ FBS. After $24 \mathrm{~h}$ of incubation, the cells on the lower surface of the filter were fixed, stained, and counted under a microscope $(\times 100$ magnification). The number of migrated cells in five random optical fields from triplicate filters was averaged. For invasion assays, the inserts of the chambers to which the cells were seeded were coated with Matrigel (Becton Dickinson Labware). The number of invaded cells in five random optical fields ( $\times 100$ magnification) was averaged from triplicate inserts.

For the wound healing assay, the cells were plated in 6 -well plates $\left(3 \times 10^{5}\right.$ cells/well $)$ and allowed to attach and reach confluence. A scratch was made using a sterile 100- $\mu$ l pipette tip and detached cells were removed by washing with PBS. Phase contrast images were taken at specified time points. The scratched wound was evaluated at $18 \mathrm{~h}$ (endothelial cells) or at $48 \mathrm{~h}$ (HCC cells) after scratching.

\section{Efficacy of dovitinib in an orthotopic HCC model}

Male athymic mice between 4 and 5 weeks of age were purchased from Shanghai Institutes for Biological Sciences (Shanghai, China). All the animal studies were conducted in accordance with the principles and procedures outlined in the guidelines of the Institutional Animal Care and Use Committee at Sun Yat-sen University Cancer Center. Mice were anesthetized by continuous inhalation of isoflurane (Baxter Healthcare, NJ).

For orthotopic xenografts, an upper abdominal midline incision was made. MHCC-97H, SMMC7721 or QGY-7703 HCC cells $\left(1 \times 10^{6}\right)$ in $30 \mu$ l of culture medium with $33 \%$ Matrigel were injected into the left lobe of the liver using an insulin syringe with a 31-gauge needle (Becton Dickinson, NJ). Two weeks later, the nude mice were randomized into three groups of 20 mice each and were treated either with $0.9 \%$ sodium chloride or 25 or $50 \mathrm{mg} / \mathrm{kg}$ of TKI258 for 14 days. On day 30 after tumor cell inoculation, the animals were weighed, euthanized, and autopsied. The liver and lungs 
were weighed and sampled for tissue sectioning. To examine lung metastases, 100 sequential lung sections $(4 \mu \mathrm{m})$ were cut from the lungs of each mouse and every tenth section was stained with hematoxylin and eosin $(\mathrm{H} \& \mathrm{E})$.

\section{Immunohistochemistry (IHC)}

Formalin-fixed and paraffin-embedded sections $4 \mu \mathrm{m}$ thick were dewaxed in xylene and a gradient of alcohols, hydrated, and washed in PBS. After pretreatment in a microwave oven (30 min in citrate buffer, $\mathrm{pH}$ 6.0), endogenous peroxidase activity was blocked by $0.3 \%$ hydrogen peroxide for $10 \mathrm{~min}$, and the sections were incubated with $10 \%$ normal goat serum for $15 \mathrm{~min}$. Primary antibodiesrabbit polyclonal anti-CD34 (Santa Cruz Biotechnology, Santa Cruz, CA), rabbit polyclonal anti-Ki67 (Abcam,
Cambridge, UK) and rabbit polyclonal anti-PARP (Abcam, Cambridge, UK) - were applied overnight in a moist chamber at $4^{\circ} \mathrm{C}$. A standard avidin-biotin peroxidase technique (DAKO, Carpinteria, CA) was applied. Briefly, biotinylated goat anti-rabbit immunoglobulin, goat anti-rat immunoglobulin, and avidin-biotin peroxidase complex were applied for $30 \mathrm{~min}$ each, with 15-min washes in PBS. The reaction was finally developed using the DAKO Liquid $\mathrm{DAB}^{+}$Substrate-Chromogen System. The methods for quantification of microvessel density (MVD), proliferation index, and apoptosis index were reported previously $[25,26]$. Briefly, the largest section of each xenograft tumor was analyzed by randomly capturing images of microscopic fields at low magnification, and the microvessels or stained cells were counted and averaged. The final results were the mean value of each case from two independent referees.

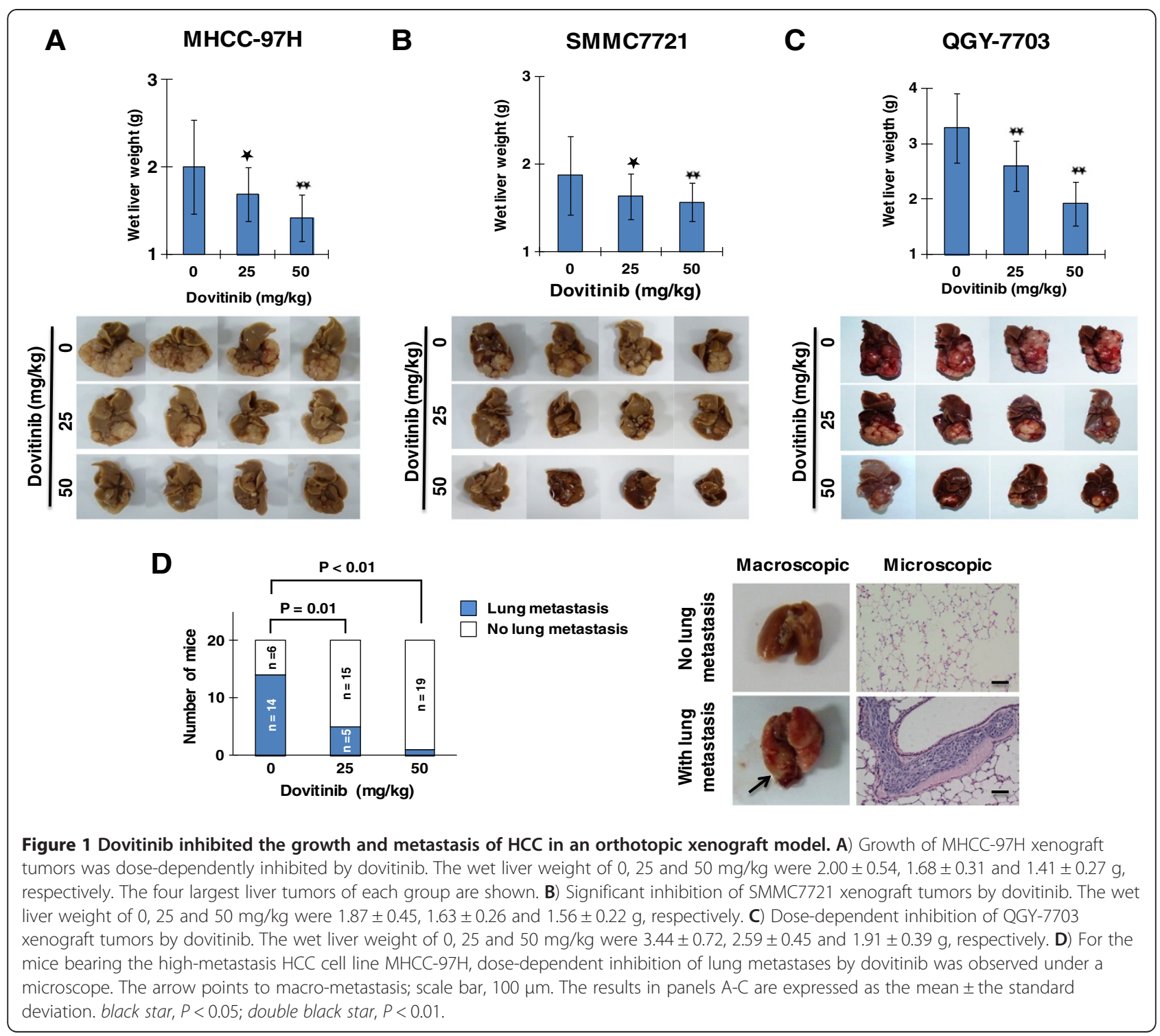


Immunoprecipitation and immunoblotting

Cells were lysed in cold RIPA buffer $(100 \mathrm{mM}$ Tris $\mathrm{HCl}$, $300 \mathrm{mM} \mathrm{NaCl}, 2 \% \mathrm{NP} 40,0.5 \%$ sodium deoxycholate) supplemented with a proteinase inhibitor cocktail (Roche, Indianapolis, IN) and a phosphatase inhibitor cocktail (Merck, Darmstadt, Germany). Protein concentration was determined using a detergent-compatible protein assay according to the manufacturer's instructions (Bio-Rad). Protein (1 mg) from each sample was immunoprecipitated overnight at $4^{\circ} \mathrm{C}$ with an antiVEGFR-2, anti-PDGFR- $\beta$, or anti-FGFR-1 (Cell Signaling Technology) antibody plus protein G/A agarose beads (Pierce). Immune complexes were washed with cold RIPA buffer containing proteinase inhibitors and phosphatase inhibitor. Proteins were eluted by boiling in SDS sample buffer, separated by SDS-PAGE, and transferred to polyvinylidene difluoride membrane (Millipore). Membranes were probed with an anti-phosphotyrosine antibody (Cell
Signaling Technology) and then stripped with stripping buffer (Abcam). To detect total VEGFR-2, PDGFR- $\beta$, and FGFR-1 levels, membranes were re-probed with the same anti-VEGFR-2, anti-PDGFR- $\beta$, and anti-FGFR-1 antibody that was used for the immunoprecipitation. Immunoblotting of phospho- ERK1/2 and ERK1/2 (Cell Signaling Technology) was performed on whole-cell lysates $(40 \mu \mathrm{g})$ with $\beta$-actin (Abcam) as a loading control.

\section{Statistical analysis}

Continuous data were expressed as median and range and were compared between groups using one-way ANOVA and Dunnett $t$ test. Categorical variables were compared using the chi-square test, or Fisher's exact test, where appropriate. All data were analyzed using the SPSS 13.0 computer program, and significant difference was defined as $P<0.05$.

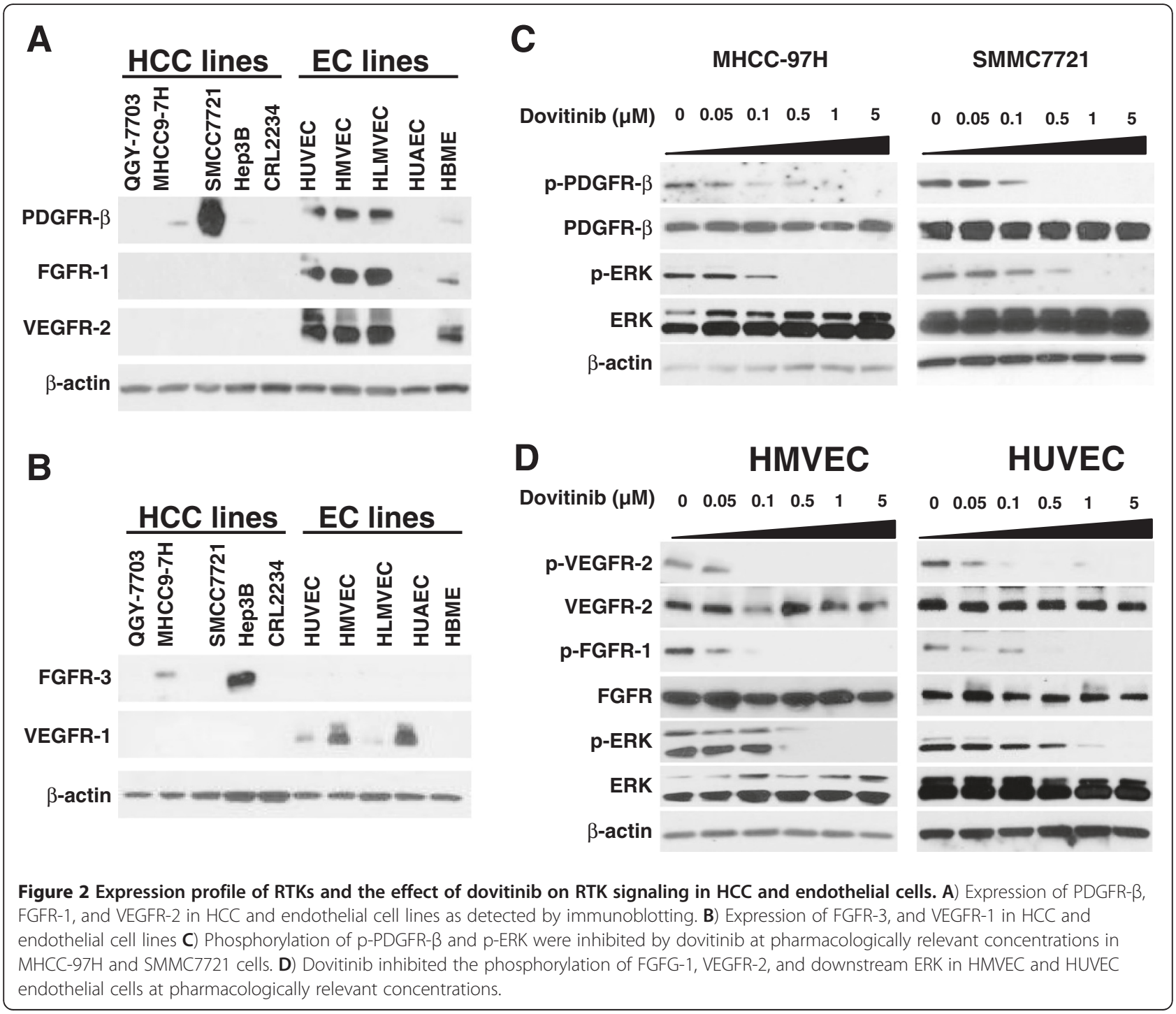




\section{Results}

Dovitinib inhibited HCC xenograft tumor growth and metastasis

The therapeutic effect of dovitinib was examined using the orthotopic HCC model. Continuous dovitinib treatment for 2 weeks at doses of 25 or $50 \mathrm{mg} / \mathrm{kg}$ was started 14 days after orthotopic injection of $\mathrm{MHCC}-97 \mathrm{H}$, SMMC7721, or QGY-7703 cells. There was no significant change in body weight of the animals in each treatment group compared with that of the control animals (data not shown). Dovitinib significantly inhibited primary tumor growth in a dose-dependent manner relative to the control group (Figure $1 \mathrm{~A}-\mathrm{C}$ ). In MHCC-97H, a HCC cell line with high metastasis capability [27], dovitinib also inhibited pulmonary metastasis in a dosedependent manner (Figure 1D).

\section{Dovitinib inhibited RTK signaling pathways in vitro}

Pharmacokinetic and pharmacodynamic studies have revealed that the pharmacologically relevant concentration of dovitinib is $0.01-0.3 \mu \mathrm{mol} / \mathrm{L}[17,18]$. To evaluate the potential effect of dovitinib at pharmacological concentration on the activation of RTK signaling pathways in vitro, we first examined the expression and activation of VEGFR, FGFR, PDGFR, Flt-3, and c-KIT in HCC cell lines and endothelial cell lines by immunoblotting. FGFR-3 was expressed by Hep3B and MHCC97H, VEGFR-1 was expressed by two endothelial cells (Figure 2B), PDGFR- $\beta$ was clearly expressed by two cell lines, MHCC-97H and SMMC7721. In contrast, four of the five endothelial cell lines homogenously expressed VEGFR-2 and FGFR-1 (Figure 2A). Flt-3 and c-KIT were undetectable in all cell lines (Additional file 1: Figure S1).

Based on the combined data of the mice and the cell lines, we focused our study on VEGFR-2, FGFR-1 AND PDGFR- $\beta$ signaling in the cells. As expected, dosedependence was found in the inhibitory effects of dovitinib on the phosphorylation of PDGFR- $\beta$, VEGFR-2, and FGFR-1, as well as their major downstream effector, the phosphorylation of ERK, on these cells (Figure 2C-D), but not the phosphorylation of Akt (Additional file 2: Figure S2B). While the levels of cleaved PARP and cleaved caspase 3 were also readily detected in dosedependence of dovitinib (Additional file 2: Figure S2A).

\section{The proliferation of endothelial cells (but not the HCC cells) was inhibited by dovitinib}

Only two HCC cell lines, MHCC-97H and SMMC7721, expressed PDGFR- $\beta$. Therefore, we compared the inhibitory effect of dovitinib on proliferation in these two lines and in endothelial cell lines. The IC50 for dovitinib to inhibit the proliferation of $\mathrm{HCC}$ cell lines was $0.87 \pm$ $0.17 \mu \mathrm{mol} / \mathrm{L}$ and $1.26 \pm 0.15 \mu \mathrm{mol} / \mathrm{L}$ for MHCC-97H and SMMC7721, respectively. While dovitinib showed robust inhibitory effect of endothelial cells under VEGFdependent conditions were $\sim 0.04 \mu \mathrm{mol} / \mathrm{L}$, which was similar to the concentrations required to inhibit activation of VEGFR-2 (Figure 3). The $\mathrm{IC}_{50}$ values of MHCC$97 \mathrm{H}$ and SMMC7721 cells were much higher than that
A

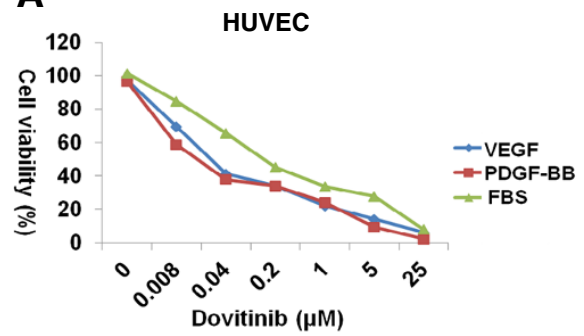

B

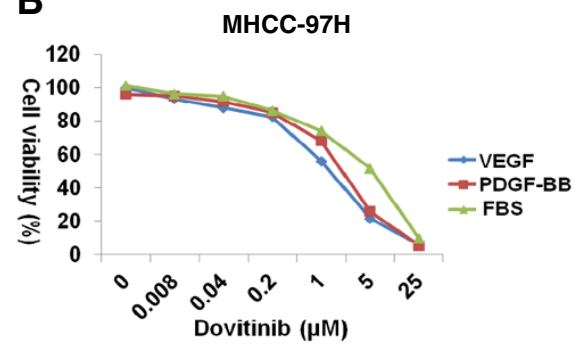

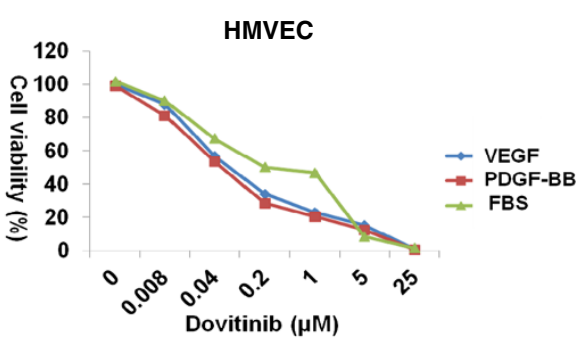

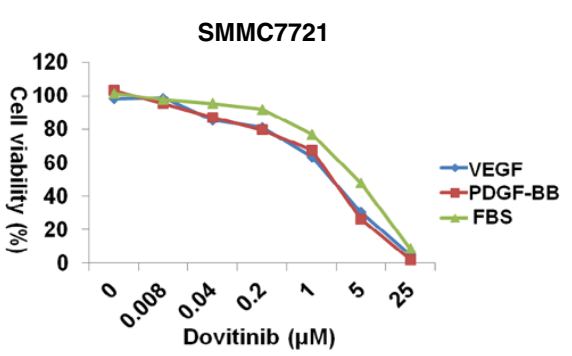

Figure 3 Dovitinib inhibited the proliferation of endothelial cells at pharmacologically relevant concentration. A) Dovitinib inhibited the proliferation of endothelial cells under VEGF, PDGF-BB dependent or normal conditions by MTS assay; results were normalized to DMSO controls. B) Proliferation of MHCC-97H and SMMC7721 HCC cells was inhibited only at high concentrations of dovitinib. 
needed to inhibit the activation of PDGFR- $\beta$, suggesting that targeting of PDGFR- $\beta$ by dovitinib did not influence the proliferation of these cells.

\section{Dovitinib inhibited the migration of endothelial cells but not of HCC cells}

Figure 4 shows that at pharmacologically relevant concentrations, dovitinib inhibited the migration and invasion of endothelial cells as evaluated by Transwell assay and wound-healing assay. The motility of MHCC-97H, SMMC7721 and QGY7703 was very weak in the woundhealing assay, and dovitinib did not show an significantly inhibitory effect on their migration of MHCC-97H.

\section{Dovitinib inhibited tumor angiogenesis in vivo}

To further elucidate the mechanism of dovitinibmediated inhibition of growth and metastasis in vivo, we collected xenograft tumor samples and examined the effect of dovitinib on the tumor vasculature as well as on HCC cell proliferation and apoptosis. Immunohistochemical analyses revealed that the markers of endothelial cell and pericyte expressed homogeneously in tumor sample (Additional file 3: Figure S3), and dovitinib significantly decreased microvessel density in MHCC-97H cells by $61.5 \%$ and $78.8 \%$ at doses of $25 \mathrm{mg} / \mathrm{kg}$ and $50 \mathrm{mg} / \mathrm{kg}$, respectively; MVD was decreased by $58.3 \%$ and $74.8 \%$, respectively, in SMMC7721 cells and by $57.9 \%$ and $82.6 \%$ in QGY-7703 cells (Figure 5). In comparison with the robust inhibition of angiogenesis, the effects of dovitinib on inhibiting proliferation and enhancing apoptosis of HCC cells in vivo were modest, although significant (Figure 6), suggesting that direct targeting HCC cells by dovitinib might not be the primary event inhibiting tumor growth in vivo.
A

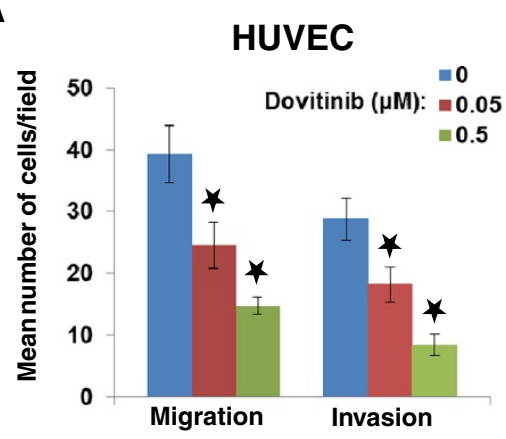

C

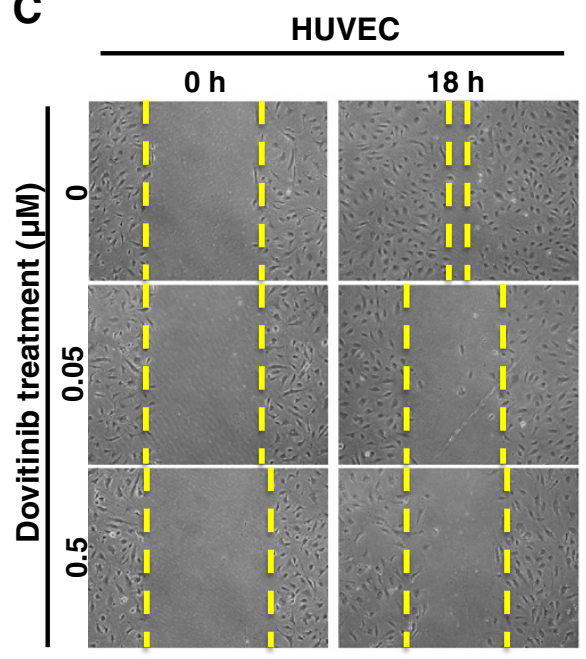

B
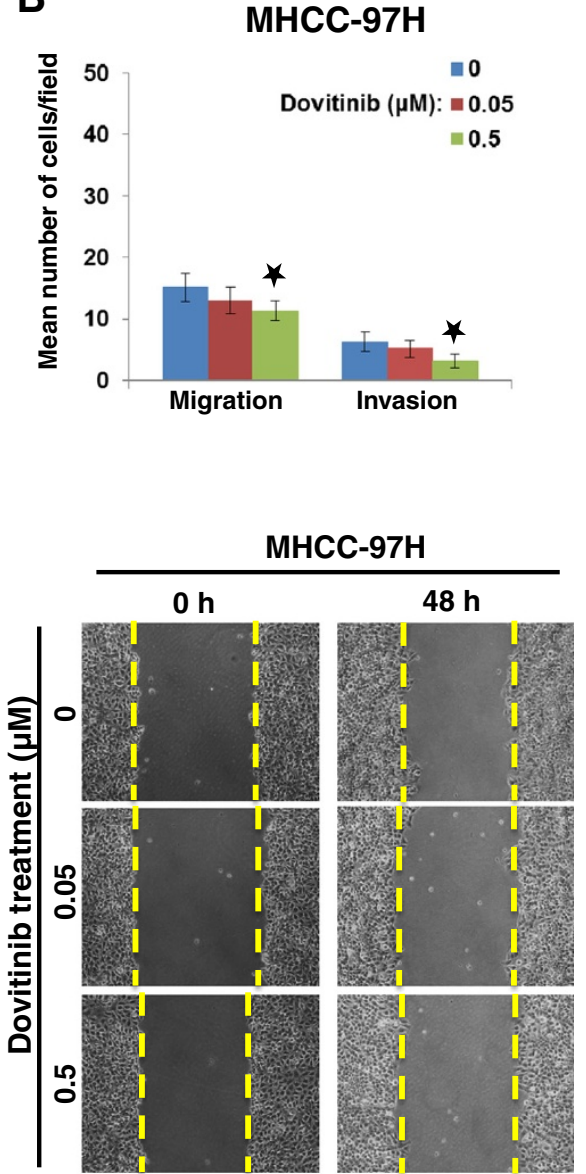

Figure 4 Dovitinib inhibited the migration and invasion of endothelial cells at pharmacologically relevant concentrations. A) As evaluated by Transwell assay, dovitinib significantly inhibited the migration and invasion of HUVEC endothelial cells in a dose-dependent manner. B) The migration and invasion of MHCC-97H cells was not inhibited by dovitinib. C) Wound healing assays showed the inhibitory effect of dovitinib on the migration of endothelial and HCC cells. Consistent with the results in the Transwell assay, the migration of HUVEC cells was inhibited, while MHCC-97H cells did not show motility. Black star, $P<0.01$ relative to control cells. 

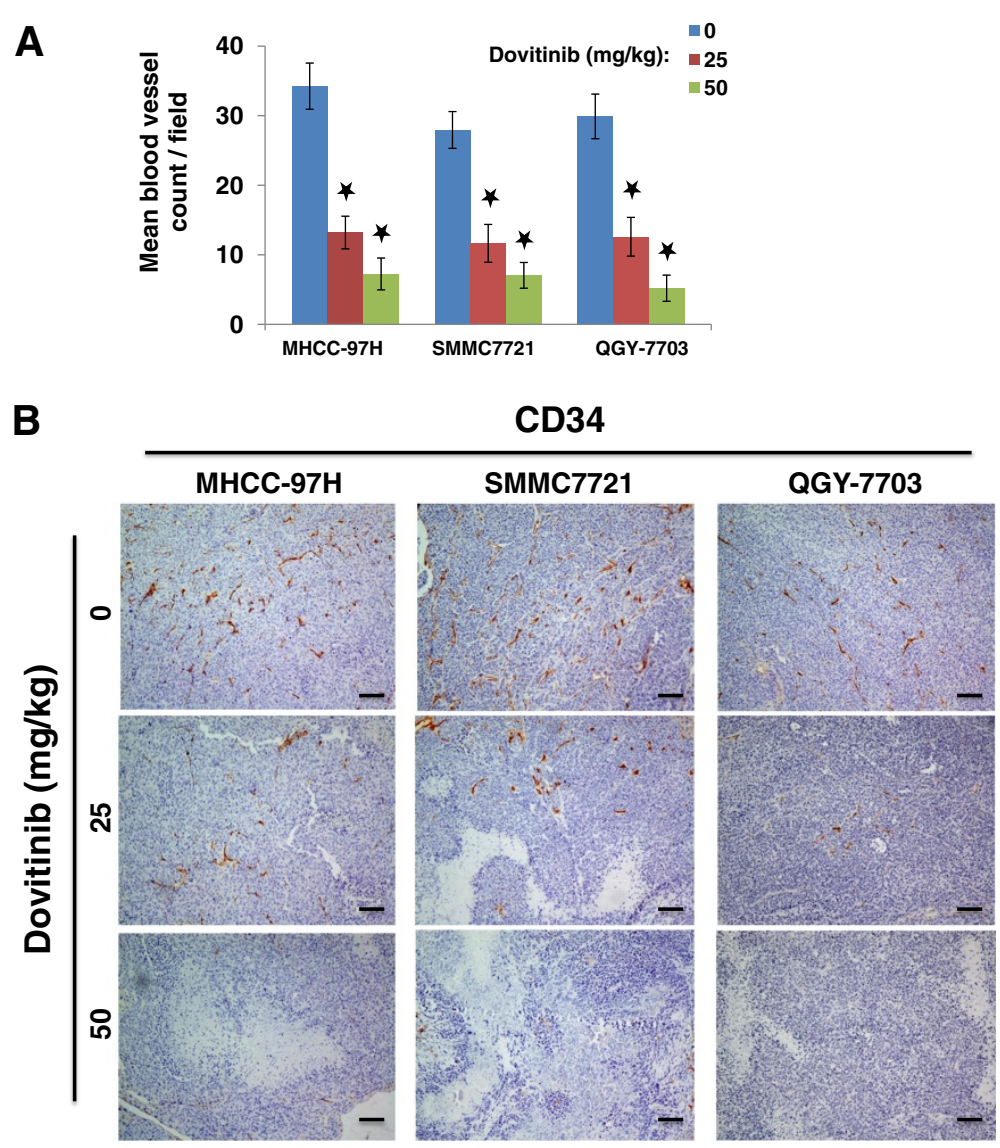

Figure 5 Dovitinib inhibited tumor angiogenesis in vivo. A) Treatment with dovitinib decreased microvessel density in a dose-dependent manner. Black star, $P<0.01$ relative to the control group. B) Immunohistochemical staining of CD34 showing microvessels in xenograft tumors. Scale bars, $100 \mu \mathrm{m}$.

\section{Discussion}

Dovitinib is currently in Phase II studies for the treatment of advanced hepatocellular carcinoma (NCT01232296), but the underlying mechanism of dovitinib in targeting HCC is not known. Our results showed that dovitinib preferentially targeted endothelial cells by inhibiting their proliferation and motility and inhibiting angiogenesis in vivo. At pharmacologically relevant concentrations, dovitinib did not affect HCC cells.

Other groups have reported that dovitinib concentrations lower than $1 \mu \mathrm{mol} / \mathrm{L}$ are sufficient to inhibit RTK signaling $[17,18]$. In cellular assays, Andrew and colleagues found that dovitinib inhibited FGFR signaling in $\mathrm{Ba} / \mathrm{Fs}$ cells lines of myeloproliferative syndrome with $\mathrm{IC}_{50}$ values of $0.09-0.15 \mu \mathrm{mol} / \mathrm{L}$ [28], consistent with our studies on endothelial cells. Finally, both clinical and preclinical pharmacodynamic studies showed that pharmacologically and clinically relevant plasma concentrations of dovitinib are $0.01-0.3 \mu \mathrm{mol} / \mathrm{L}[17,18]$.

A recent study using a high concentration $(1.727 \mu \mathrm{M})$ of dovitinib reported that anchorage-independent growth and FGF-induced motility of HCC cells was inhibited [29]. Unfortunately, this study did not evaluate the effect of dovitinib on endothelial cells, and the concentration used was much higher than a pharmacologically relevant dose. In our study, dovitinib at $0.1 \mu \mathrm{mol} / \mathrm{L}$ did not affect the viability or proliferation of HCC cell lines in vitro. In contrast, it did inhibit endothelial cell proliferation and motility at concentrations that also inhibited VEGFR and FGFR signaling in these cells. Studies of HCC xenografts treated with pharmacologically relevant concentrations of dovitinib showed more effect on the inhibition of tumor angiogenesis in vivo than on proliferation or apoptosis. Taken together, these data indicate that dovitinib acts preferentially to target tumor vasculature rather than cancer cells in the treatment of HCC.

Some previous studies have reported that high expression of the angiogenic factors VEGF, basic FGF, and platelet-derived growth factor receptor are detected in patients with HCC, suggesting that VEGFR, FGFR, and PDGFR are likely targets of dovitinib. Our analysis of 


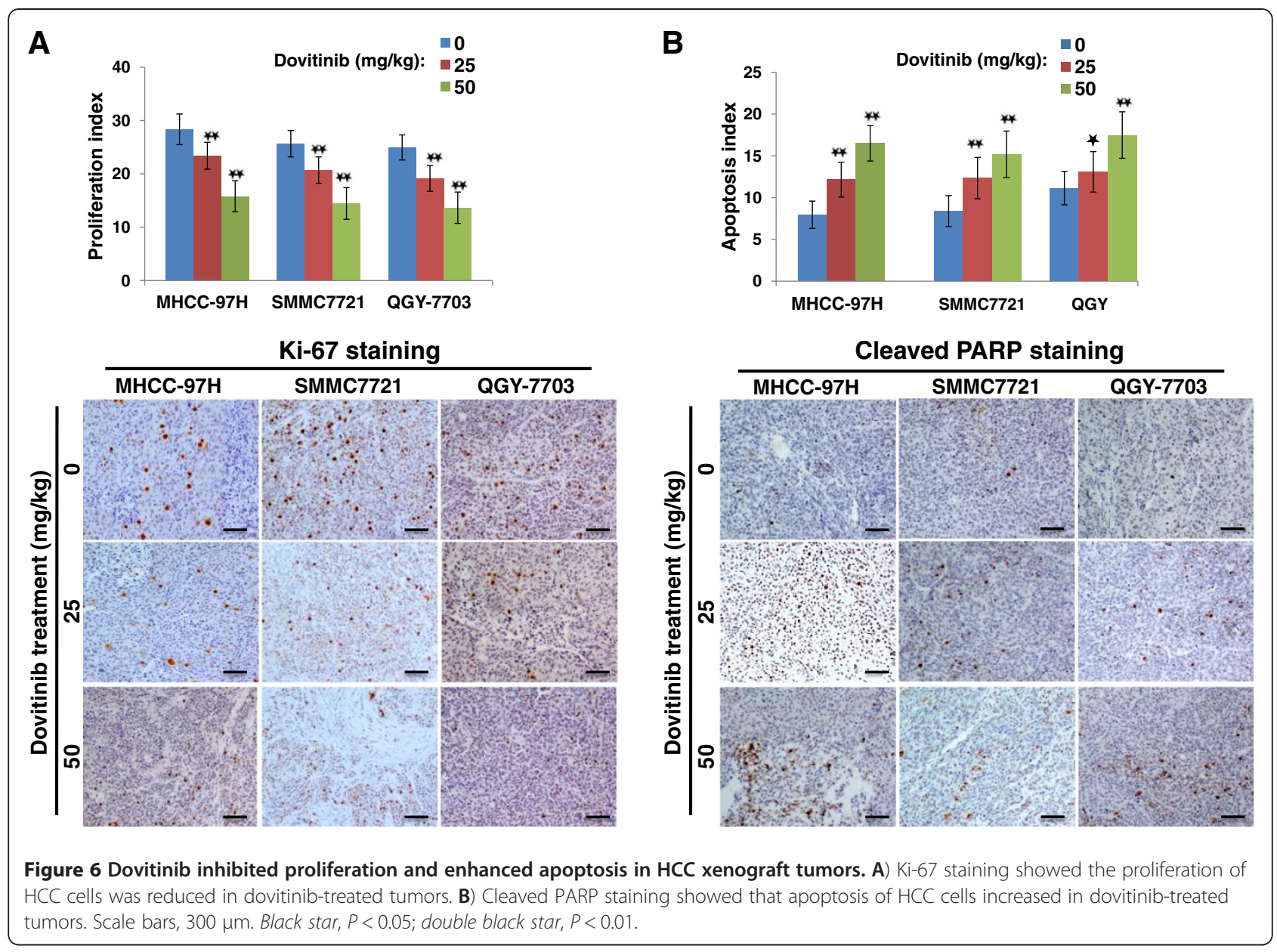

HCC and endothelial cell lines found that, of the known dovitinib-sensitive RTKs, only PDGFR- $\beta$ was expressed by SMMC7721 and MHCC-97H cells, where VEGFR-2 and FGFR-1 were highly expressed by endothelial cells. Although high PDGFR- $\beta$ expression has been correlated with HCC progression [30], our in vitro studies showed that dovitinib inhibition of PDGFR signaling was not sufficient to inhibit the proliferation of HCC cells. Thus, PDGFR signaling in HCC cells is likely through redundant growth signaling pathways. In contrast, dovitinib inhibited the phosphorylation of VEGFR-2 and FGFR-1 in endothelial cells at similar concentrations, indicating the important role of VEGFR and FGFR signaling in the proliferation of endothelial cells.

The endothelial cells recruited to the tumor tissue are not only related to blood perfusion of the tumor, but they are also believed to be involved in the cancer-stromal cell interaction favoring tumor growth [31]. However, some believe that normal endothelial cells may be the barrier to hematogenous metastasis [32]. Blocking the adhesion of tumor cells to endothelial cells prevents the implantation of tumors cells in capillaries, thus inhibiting the migration of tumor cells in the circulation [33]. In our previous study, we found in HCC tissues that a distinct pattern of endothelial structures, endothelium-coated tumor clusters, was an independent predictor for survival and recurrence in patients with HCC [6]. Endothelial cells facilitate the efficiency of metastasis, irrespective of the invasiveness of tumor cells [6]. In our study here, a pharmacologically relevant concentration of dovitinib, $0.1 \mu \mathrm{mol} / \mathrm{L}$, did not affect the migration or invasion of HCC cell lines in vitro. In contrast, dovitinib did inhibit endothelial cell migration and invasion and did so at concentrations that also inhibited VEGFR and FGFR signaling in these cells. Moreover, studies of orthotopic HCC models treated with pharmacologically relevant concentrations of dovitinib inhibited lung metastasis in vivo. These findings suggest that the migration of endothelial cells could be an important step in HCC metastasis by providing an envelope that protects the tumor cells in circulation [6].

\section{Conclusion}

In summary, we found that at pharmacologically relevant concentrations, dovitinib targeted endothelial cells, but not $\mathrm{HCC}$ cells, in inhibiting $\mathrm{HCC}$ growth and 
metastasis. To our knowledge, this is the first study to clarify the cellular target of dovitinib in the treatment of $\mathrm{HCC}$, which might be helpful for future development of targeted therapy in HCC.

\section{Additional files}

Additional file 1: Figure S1. The markers of endothelial cell and pericyte expressed homogeneously in tumor sample.

A) Immunohistochemical staining of CD31 in the tumor sample. B) CD34. C) CD105. D) SMA.

Additional file 2: Figure S2. C-KIT and Flt-3 were undetectable in HCC cell lines and endothelial cell lines.

Additional file 3: Figure S3. Effects of dovitinib on apoptosis and the phosphorylation of Akt in HCC cell and endothelial cell lines. A) The levels of cleaved PARP and cleaved caspase 3 were also readily detected in dose-dependence of dovitinib, but it do not show significant difference between on HCC cell and endothelial cell lines. B) Dovitinib does not reduced the basal phosphorylation levels of Akt in HCCcell lines.

\section{Competing interests}

The authors declare that they have no competing interests.

\section{Authors' contributions}

RPG and CNQ are responsible for the study design. ZYC, MS, and CNQ performed the experiments and draft the manuscript. LXP, XJL, ZXG, SHL, and $C Z$ collected the data. ZYC, RPG, and CNQ participated in the data analysis and interpretation. All authors read and approved the final manuscript.

\section{The novelty and impact of the work}

Dovitinib is a receptor tyrosine kinase (RTK) inhibitor in clinical trials for the treatment of hepatocellular carcinoma (HCC). We do not have a full understanding of the cellular target(s) of dovitinib in HCC treatment. By using five HCC cell lines and five endothelial cell lines in validating targets, we found that dovitinib inhibited HCC growth and metastasis preferentially through an antiangiogenic mechanism, not through direct targeting of HCC cells.

\section{Acknowledgements}

This work was supported by grants from the National Natural Science Foundation of China (No. 81172037/H1606; No. 81030043), Guang Dong Province Science Foundation of China (No. 2009B080701012; No. 2008B030301322) and the Van Andel Foundation. We thank David Nadziejka, Grand Rapids, Michigan, for critical reading of the manuscript.

\section{Author details}

${ }^{1}$ Department of Hepatobiliary Surgery, Sun Yat-sen University Cancer Center, 651 Dongfeng Road East, Guangzhou 510060, China. ${ }^{2}$ State Key Laboratory of Oncology in South China, Sun Yat-sen University Cancer Center, 651 Dongfeng East Road, Guangzhou 510060, People's Republic of China. ${ }^{3}$ Laboratory of Cancer and Developmental Cell Biology, Van Andel Research Institute, 333 Bostwick Ave. NE, Grand Rapids, Ml 49503, USA. ${ }^{4}$ Department of Neuro-Oncology, University of Texas MD Anderson Cancer Center, 6767 Bertner Ave., Unit 1002, BSRB S5.8116, Houston, TX 77030, USA. ${ }^{5}$ Department of Hepatobilliary Surgery, 1st Affiliated Hospital to Guangzhou University of Chinese Medicine, 16 Jichang Road, Guangzhou 510405, China.

Received: 19 August 2012 Accepted: 19 November 2012 Published: 10 December 2012

\section{References}

1. Bruix J, Llovet JM: Major achievements in hepatocellular carcinoma. Lancet 2009, 373:614-616.

2. Yang JD, Roberts LR: Hepatocellular carcinoma: a global view. Nat Rev Gastroenterol Hepatol 2010, 7:448-458.
3. Hao MZ, Lin HL, Chen Q, Ye YB, Chen QZ, Chen MS: Efficacy of transcatheter arterial chemoembolization combined with cytokine-induced killer cell therapy on hepatocellular carcinoma: a comparative study. Chin J Cancer 2010, 29:172-177.

4. Qin L, Bromberg-White JL, Qian CN: Opportunities and challenges in tumor angiogenesis research: back and forth between bench and bed. Adv Cancer Res 2012, 113:191-239.

5. Budhu A, Forgues M, Ye QH, Jia HL, He P, Zanetti KA, Kammula US, Chen Y, Qin $L X$, Tang ZY, Wang XW: Prediction of venous metastases, recurrence, and prognosis in hepatocellular carcinoma based on a unique immune response signature of the liver microenvironment. Cancer Cell 2006, 10:99-111.

6. Ding T, Xu J, Zhang Y, Guo RP, Wu WC, Zhang SD, Qian CN, Zheng L: Endothelium-coated tumor clusters are associated with poor prognosis and micrometastasis of hepatocellular carcinoma after resection. Cancer 2011, 117:4878-4889.

7. Chen JA, Shi M, Li JQ, Qian CN: Angiogenesis: multiple masks in hepatocellular carcinoma and liver regeneration. Hepatol Int 2010, 4:537-547.

8. Park YN, Kim YB, Yang KM, Park C: Increased expression of vascular endothelial growth factor and angiogenesis in the early stage of multistep hepatocarcinogenesis. Arch Pathol Lab Med 2000, 124:1061-1065.

9. Hu Z, Evarts RP, Fujio K, Omori N, Omori M, Marsden ER, Thorgeirsson SS: Expression of transforming growth factor alpha/epidermal growth factor receptor, hepatocyte growth factor/c-met and acidic fibroblast growth factor/fibroblast growth factor receptors during hepatocarcinogenesis. Carcinogenesis 1996, 17:931-938.

10. Maass T, Thieringer FR, Mann A, Longerich T, Schirmacher P, Strand D, Hansen T, Galle PR, Teufel A, Kanzler S: Liver specific overexpression of platelet-derived growth factor-B accelerates liver cancer development in chemically induced liver carcinogenesis. Int J Cancer 2010, 128:1259-1268.

11. Guo RP, Zhong C, Shi M, Zhang CQ, Wei W, Zhang YQ, Li JQ: Clinical value of apoptosis and angiogenesis factors in estimating the prognosis of hepatocellular carcinoma. J Cancer Res Clin Oncol 2006, 132:547-555.

12. Cheng AL, Kang YK, Chen Z, Tsao CJ, Qin S, Kim JS, Luo R, Feng J, Ye S, Yang TS, et al: Efficacy and safety of sorafenib in patients in the AsiaPacific region with advanced hepatocellular carcinoma: a phase III randomised, double-blind, placebo-controlled trial. Lancet Oncol 2009, 10:25-34.

13. Di Maio M, Daniele B, Perrone F: Targeted therapies: role of sorafenib in HCC patients with compromised liver function. Nat Rev Clin Oncol 2009, 6:505-506.

14. Llovet JM, Ricci S, Mazzaferro V, Hilgard P, Gane E, Blanc JF, de Oliveira AC, Santoro A, Raoul JL, Forner A, et al: Sorafenib in advanced hepatocellular carcinoma. N Engl J Med 2008, 359:378-390.

15. Taeger J, Moser C, Hellerbrand C, Mycielska ME, Glockzin G, Schlitt HJ, Geissler EK, Stoeltzing O, Lang SA: Targeting FGFR/PDGFR/VEGFR impairs tumor growth, angiogenesis, and metastasis by effects on tumor cells, endothelial cells, and pericytes in pancreatic cancer. Mol Cancer Ther 2011, 10:2157-2167.

16. Kim KB, Chesney J, Robinson D, Gardner H, Shi MM, Kirkwood JM: Phase I/II and pharmacodynamic study of dovitinib (TKI258), an inhibitor of fibroblast growth factor receptors and VEGF receptors, in patients with advanced melanoma. Clin Cancer Res 2011, 17:7451-7461.

17. Lee SH, Lopes de Menezes D, Vora J, Harris A, Ye H, Nordahl L, Garrett E, Samara E, Aukerman SL, Gelb AB, Heise C: In vivo target modulation and biological activity of CHIR-258, a multitargeted growth factor receptor kinase inhibitor, in colon cancer models. Clin Cancer Res 2005, 11:3633-3641

18. de Menezes DE L, Peng J, Garrett EN, Louie SG, Lee SH, Wiesmann M, Tang Y, Shephard L, Goldbeck C, Oei Y, et al: CHIR-258: a potent inhibitor of FLT3 kinase in experimental tumor xenograft models of human acute myelogenous leukemia. Clin Cancer Res 2005, 11:5281-5291.

19. Xin X, Abrams TJ, Hollenbach PW, Rendahl KG, Tang Y, Oei YA, Embry MG, Swinarski DE, Garrett EN, Pryer NK, et al: CHIR-258 is efficacious in a newly developed fibroblast growth factor receptor 3-expressing orthotopic multiple myeloma model in mice. Clin Cancer Res 2006, 12:4908-4915.

20. Chen KF, Chen HL, Liu CY, Tai WT, Ichikawa K, Chen PJ, Cheng AL: Dovitinib sensitizes hepatocellular carcinoma cells to TRAIL and tigatuzumab, a novel anti-DR5 antibody, through SHP-1-dependent inhibition of STAT3. Biochem Pharmacol 2012, 83:769-777.

21. Tai WT, Cheng AL, Shiau CW, Liu CY, Ko CH, Lin MW, Chen PJ, Chen KF: Dovitinib induces apoptosis and overcomes sorafenib resistance in 
hepatocellular carcinoma through SHP-1-mediated inhibition of STAT3. Mol Cancer Ther 2011, 11:452-463.

22. Greenman C, Stephens P, Smith R, Dalgliesh GL, Hunter C, Bignell G, Davies H, Teague J, Butler A, Stevens C, et al: Patterns of somatic mutation in human cancer genomes. Nature 2007, 446:153-158.

23. Yan W, Bentley B, Shao R: Distinct angiogenic mediators are required for basic fibroblast growth factor- and vascular endothelial growth factor-induced angiogenesis: the role of cytoplasmic tyrosine kinase c-Abl in tumor angiogenesis. Mol Biol Cell 2008, 19:2278-2288.

24. Mendelson K, Swendeman S, Saftig P, Blobel CP: Stimulation of platelet-derived growth factor receptor beta (PDGFRbeta) activates ADAM17 and promotes metalloproteinase-dependent cross-talk between the PDGFRbeta and epidermal growth factor receptor (EGFR) signaling pathways. J Biol Chem 2010, 285:25024-25032.

25. Huang D, Ding Y, Luo WM, Bender S, Qian CN, Kort E, Zhang ZF, VandenBeldt K, Duesbery NS, Resau JH, Teh BT: Inhibition of MAPK kinase signaling pathways suppressed renal cell carcinoma growth and angiogenesis in vivo. Cancer Res 2008, 68:81-88.

26. Chen ZY, Wei W, Guo ZX, Lin JR, Shi M, Guo RP: Morphologic classification of microvessels in hepatocellular carcinoma is associated with the prognosis after resection. J Gastroenterol Hepatol 2011, 26:866-874.

27. Gu Y, Zhu CF, Dai YL, Zhong Q, Sun B: Inhibitory effects of genistein on metastasis of human hepatocellular carcinoma. World J Gastroenterol 2009, 15:4952-4957.

28. Chase A, Grand FH, Cross NC: Activity of TKI258 against primary cells and cell lines with FGFR1 fusion genes associated with the 8p11 myeloproliferative syndrome. Blood 2007, 110:3729-3734.

29. Huynh H, Chow PK, Tai WM, Choo SP, Chung AY, Ong HS, Soo KC, Ong R, Linnartz R, Shi MM: Dovitinib demonstrates antitumor and antimetastatic activities in xenograft models of hepatocellular carcinoma. J Hepatol 2011, 56:595-601.

30. Chen L, Shi Y, Jiang CY, Wei LX, Lv YL, Wang YL, Dai GH: Coexpression of PDGFR-alpha, PDGFR-beta and VEGF as a prognostic factor in patients with hepatocellular carcinoma. Int I Biol Markers 2011, 26:108-116.

31. Franses JW, Edelman ER: The evolution of endothelial regulatory paradigms in cancer biology and vascular repair. Cancer Res 2011, 71:7339-7344

32. Saiki I, Koike C, Obata A, Fujii H, Murata J, Kiso M, Hasegawa A, Komazawa H, Tsukada H, Azuma I, et al: Functional role of sialyl Lewis X and fibronectin-derived RGDS peptide analogue on tumor-cell arrest in lungs followed by extravasation. Int I Cancer 1996, 65:833-839.

33. Mannori G, Santoro D, Carter L, Corless C, Nelson RM, Bevilacqua MP: Inhibition of colon carcinoma cell lung colony formation by a soluble form of E-selectin. Am J Pathol 1997, 151:233-243.

doi:10.1186/1479-5876-10-245

Cite this article as: Chen et al: Dovitinib preferentially targets endothelial cells rather than cancer cells for the inhibition of hepatocellular carcinoma growth and metastasis. Journal of Translational Medicine 2012 10:245.

\section{Submit your next manuscript to BioMed Central and take full advantage of:}

- Convenient online submission

- Thorough peer review

- No space constraints or color figure charges

- Immediate publication on acceptance

- Inclusion in PubMed, CAS, Scopus and Google Scholar

- Research which is freely available for redistribution

Submit your manuscript at www.biomedcentral.com/submit
( Biomed Central 